\title{
How the ecology and evolution of the COVID-19 pandemic changed learning
}

\author{
Marcus Lashley ${ }^{1}$, Miguel Acevedo ${ }^{1}$, Sehoya Cotner $^{2}$, and Christopher Lortie ${ }^{3}$ \\ ${ }^{1}$ University of Florida \\ ${ }^{2}$ University of Minnesota Twin Cities \\ ${ }^{3}$ York University - Keele Campus
}

August 3, 2020

\begin{abstract}
The coronavirus disease 2019 (COVID-19) pandemic introduced an abrupt change in human behavior globally. Here, we discuss unique insights into the eco-evolutionary role of pathogens in ecosystems and present data that indicates the pandemic can fundamentally change our learning choices. This pathogen has indirectly affected many organisms and processes by globally changing the behavior of humans to avoid being infected. The pandemic also changed our learning behavior by affecting the relative importance of information and forcing teaching and learning into a framework that accommodates human behavioral measures to avoid disease transmission. Not only are these indirect effects on the environment occurring through a unique mechanistic pathway in ecology, the pandemic along with its effects on us provides a profound example of the role risk can play in the transmission of information between the at-risk. Ultimately, these changes in our learning behavior led to this special issue "Taking learning online in Ecology and Evolution." The special issue was a call to the community to take learning in new directions, including online and distributed experiences. The topics examined include a significant component of DIY ecology and evolution that is experiential and but done individually, opportunities to use online tools and apps to be more inclusive, student-focused strategies for teaching online, how to reinvent conferences, strategies to retain experiential learning safely, emerging forms of teaching such as citizen science, apps and podcasting, and ideas on how to accommodate ever changing constraints in the college classroom, to name a few. The collective consensus in our fields is that these times are challenging but we can continue to improve and innovate on existing developments, and more broadly and importantly, this situation may provide an opportunity to reset some of the existing practices that fail to promote an effective and inclusive learning environment.
\end{abstract}

A unique pathway for indirect effects of COVID-19

Theory in ecology and evolution helps us understand patterns and processes in natural systems and in human society. The coronavirus disease 2019 (COVID-19) pandemic is a profound example of a pathogen generating indirect effects by altering host behavior. Interestingly, this may be the only example of those indirect effects generated by a pathogen being primarily related to behavioral changes of individuals of the host species who were not infected. Six months since the first documented infection, the pathogen has infected only a small proportion of the global population (15 million confirmed cases as of July 30, 2020; Dong et al. 2020), yet it has resulted in widespread changes in the way billions of people live (e.g., Corlett et al. 2020, Gössling et al. 2020, Rutz et al. 2020). These behavioral changes, arising primarily to avoid infection, have had cascading indirect effects of the pathogen on the environment such as decreased concentrations of some greenhouse gasses in the atmosphere, changes in air quality and environmental pollution, and decreases in anthropogenic sound (e.g., Corlett et al. 2020, Chen et al. 2020, Isaifan 2020, Zambrano-Monserrate et al. 2020). Plus, the decrease in human activity (i.e., anthropause) has provided a strong natural experimental framework for researchers to uncover how humans affect wildlife communities (Rutz et al. 2020). Based on ecological and 
evolutionary theory, these indirect effects from pathogens changing the behavior of their hosts should be prevalent in nature because we know organisms-humans and many other species-commonly change their behavior in response to pathogens-either as a result of getting infected, or to avoid getting infected (Curtis 2014, Weinstein et al. 2018). However, a recent and comprehensive review (i.e., Buck and Ripple 2017) only uncovered one example where a pathogen generated indirect effects by infecting the host (i.e.., a pathogen indirectly affected prey abundance by reducing feeding rate in the predatory crawfish it infected; Haddaway et al. 2012) and found no published examples of indirect effects from a pathogen generated by behavioral avoidance of getting infected (Buck and Ripple 2017). Indeed, indirect effects stemming from host avoidance of parasites is rare as well (Buck 2019). Given that the majority of people changing their behavior has not been infected, COVID-19 has provided a compelling and rare example of indirect effects by a pathogen being caused by behavioral avoidance of infection. Likewise, COVID-19 provides us with a stark reminder that humans are a part of, and not separate from, the principle eco-evolutionary processes that shape our world. We as ecologists and evolutionary biologists can use the pandemic to advance our knowledge base, and also use our knowledge base to inform responses to the pandemic.

The pandemic has changed what we seek to learn

Online learning is a deep and rich field of research, tools, and ideas. The use of the term 'online learning' is not universal and can describe different concepts (Moore et al. 2011). It can refer to learning entirely online or more broadly the use of online tools and virtual spaces to engage and support learning (Wallace 2003). The pandemic has caused many shifts including behavioral responses to interest in online learning, teaching, and information technology. Some of these changes are driven by necessity, including emergency delivery of teaching content online but also may stem from fear of infection. Further, interest in online learning can shift because of emotional drivers; to explore this idea, we can turn to data on human web searches (i.e., google trends). Predicting human behaviour using web searches is a well-established field of research in consumer studies (Preis et al. 2013) and other disciplines (Nuti et al. 2014), and the evidence suggests that volume of searches provides a useful predictive guide to the near future in behaviour (Goel et al. 2010). This tool estimates the relative interest (or trends) of internet users globally by comparing the relative frequencies of search queries between different time periods, allowing us to infer change in human priorities. There are numerous examples of this approach, and current examples have involved using Google Trends data to examine indicators of private consumption (Vosen and Schmidt 2011), predicted cryptocurrency market values (Kristoufek 2013), trading behavior in financial markets (Preis et al. 2013), human health and healthcare (Heerfordt and Heerfordt 2020, Nuti et al. 2014), and-more pertinent to this discussion-shifts in consumer choices during the pandemic (Claudia et al. 2020). Specifically, the Google Trends tool provides data and trend analyses by key terms through time. While the overall predictive accuracy of Google Trends has been challenged by periods of unusually high search prevalences (i.e. ephemeral spikes; Butler 2013), recent developments have improved its predictive accuracy (Kandula and Shaman 2019). Our primary aim here was to compare the dynamics of relative interests in different types of information during the pandemic globally using Google Trends (Choi and Varian 2012). Understanding that limitations exist with Google Trends, we saw an opportunity to frame the concepts developed in this special issue within this larger, global conversation and engagement with information to understand how we fit in to the ecology and evolution of the pandemic but also how our learning environment must change in response.

To do this, we first examined the relative interests in topics related to risk ("death"), resources ("money"), and reproduction ("love"), three currencies we often value in natural systems in our fields. Google trends indicated dramatic shifts in relative interest between these topics at the onset of the COVID-19 pandemic. Google searches between the same January-June period in 2019 and then again in 2020 showed that our relative interests in reproduction (google search global topics related to "love"), risks (google search global topics related to "death"), and resources (google search global topics related to "money") dramatically shifted in 2020 tracking increases in confirmed infections (https://github.com/maacevedo/covid19gtrends). While in 2019 , topics of "love" were the most frequently searched of these three, in 2020, with an increasing number of infections, "love" was replaced by topics related to "death" (Figure 1). A shift in relative importance of reproduction and risk of mortality can be expected based on ecological and evolutionary theory on the 
effects of predation risk (Lima and Dill 1990) and risk of infection (Weinstein et al. 2018), but we found it interesting that this pattern seems to have emerged in global patterns of online searches related to the pandemic. These changes may stem from the desire to learn about COVID-19 so that one can better calculate the risk it poses and determine the appropriate behavioral response-especially given that other authors have attributed to the pandemic a heightened level of fear in people (Ahorsu et al. 2020, Lin 2020). In essence, risks from COVID-19 seem to have, at least temporarily, changed the relative importance of the information we seek to learn. Changes in density and behavior (Lima and Dill 1990, Brown et al 1999) in response to fear of predation have been common in ecological literature. However, demonstrating that individuals of any species fundamentally change how they value different types of information is difficult to measure (Clinchy et al. 2011). Understanding these patterns and processes in humans can inform our understanding of the role emotion can play in natural communities (Clinchy et al. 2011, Frey et al. 2014). These data provide solid evidence that understanding how humans interact with their environment and other organisms may provide us with rare opportunities to identify ecological and evolutionary mechanisms not easily measured in other organisms.

The pandemic has transformed how we approach teaching and learning

Avoidance of COVID-19 infection has led to a wide-spread change in the way we approach teaching and learning. Psychological stressors affecting cognition in animals can be similar in humans (Clinchy et al. 2013). While there is less information on how fear affects how or what animals teach each other, COVID-19 has certainly changed human behavior in this capacity. The pandemic has caused an abrupt shift in content delivery across disciplines and globally, an alignment in interest among educators that is unprecedented (e.g., Bao 2020, Basilaia and Kvavadze 2020, Crawford et al 2020, Zhang et al. 2020). This alignment may have been predicted from ecological theory as risk (e.g., risk of predation, risk of infection) tends to constrain decisions to what is safe for the at-risk (Hutchinson and Gigerenzer 2005, Kemp 2005, Winnie et al. 2006). Afterall, the fitness consequence of being eaten (or fatally infected in this case) are more severe than missing an opportunity to learn, or procure resources or reproduce for that matter. Because the pandemic forced the abrupt shutdown of universities for safety reasons, in effect it forced all disciplines to move online (Crawford et al. 2020) for "emergency remote instruction" (Hodges et al. 2020). Thus, among educators, COVID-19 has simplified how we approach learning in a sense by giving us all a common goal of moving to emergency remote instruction.

Although measures may have been similarly applied across disciplines, the effects of moving online across disciplines are asymmetrical. Disciplines that require human contact such as medicine (Ahmed et al. 2020a, Rose 2020) are perhaps most severely affected. However, field-based disciplines such as ecology, evolution, and conservation biology are also dramatically affected (Corlett et al. 2020). Although the pandemic has affected us all, different institutionalized and individual strategies to accommodate the threat and burden on education have emerged (e.g., Bao 2020, Basilaia and Kvavadze 2020, Crawford et al 2020, Zhang et al. 2020). The unifying theme is that education has transitioned, rapidly and without time for much preparation, to online delivery, regardless of other nuances in responses or the discipline being affected. Interestingly, like the famous hockey stick graph in climate change literature (i.e., Mann et al. 1999), this unification of interest in online learning is reflected in an abrupt upturn in google search interest-one which nearly perfectly parallels that of new COVID-19 infections per week, at least up until mid-May when classes end for the academic year in many parts of the world (Figure 2). This correlation suggests that interest in strategies for effective remote instruction increased as risk from COVID-19 increased; again, we used google search interest and number of new infections as proxies for interest in the topic overall and perceived risk of infection.

Although aspects of our response have been unified, the pandemic has also highlighted inequities in many aspects of our daily experiences (Ahmed et al. 2020b), such as access to healthcare (Hooper et al 2020), and job and housing security (Yancy 2020; Raifman and Raifman 2020). COVID-19 has also magnified some educational inequities, whereby those previously disadvantaged or at risk of attrition find themselves even more disadvantaged and at greater risk. Students from lower socioeconomic backgrounds are more likely to face challenges from e.g., unreliable internet, added demands of child- and elder-care, job loss, or the need 
to work as "essential" employees-furthering their risk of contracting COVID-19 (Winter 2020, CDC 2020) . In many places where we work, low socioeconomic status overlaps strongly with ethnic and racial categories; consequently, the students we most need to retain are also the most likely to be at greatest risk, including from an educational standpoint with inclusion and retention, during the pandemic. Thus, an added challenge for educators is to not only teach using novel delivery modalities, but also to redouble our efforts at inclusive teaching.

The goals of this special issue

This pandemic has forced many-if not most-of us to reconsider how we communicate information. The Academic Practice section ofEcology and Evolution was developed to explore how we do things in our disciplines (Moore et al. 2017). This special issue of Academic Practice provides a forum for our community to present experiences and ideas about the best practices for moving our disciplines online in a focused, accessible, and clearly organized manner. The ultimate purpose was "to provide a rapid outlet to share timely innovations and discoveries for online teaching and learning in ecology and evolution." However, the pandemic has reached every corner of our society and will change more than just course delivery. Thus, this special issue also covers issues related to meetings and conferences, development of scientific products, strategies to promote open science, how we can best promote equity, diversity and inclusion in the transition to remote instruction, and engaging non-academic audiences. We wanted the contributions to be a resource for the ecology and evolutionary biology communities as a whole as we adapt to the COVID-19 crisis, so we emphasized rapid handling of manuscripts, short contributions, and inclusion of tools and resources that facilitate adoption. We have already accepted contributions related to x (e.g., cite), y (e.g., cite), z (e.g., cite), contributions highlighting sources of inequity and strategies to be more inclusive in online delivery (e.g., cite), and ideas for use of tools, apps, and novel media to enhance engagement (e.g., cite). The COVID-19 crisis demanded action, and with over 40 submissions to this special issue by our community, you have risen to the occasion. We applaud members of our community for contributing their ideas and experiences in this forum and hope that this special issue provides a start to a rich literature base to take learning online in ecology and evolution and beyond.

\section{Literature Cited}

Ahmed, F., Ahmed, N. E., Pissarides, C., \& Stiglitz, J. (2020b). Why inequality could spread COVID-19. The Lancet Public Health, 5(5), e240.

Ahmed, H., Allaf, M., \& Elghazaly, H. (2020a). COVID-19 and medical education. The Lancet Infectious Diseases.

Ahorsu, D. K., Lin, C. Y., Imani, V., Saffari, M., Griffiths, M. D., \& Pakpour, A. H. (2020). The fear of COVID-19 scale: development and initial validation. International journal of mental health and addiction .

Bao, W. (2020). COVID-19 and online teaching in higher education: A case study of Peking University. Human Behavior and Emerging Technologies , 2 (2), 113-115.

Basilaia, G., \& Kvavadze, D. (2020). Transition to online education in schools during a SARS-CoV-2 coronavirus (COVID-19) pandemic in Georgia.Pedagogical Research , 5 (4), 1-9.

Brown, J. S., Laundre, J. W., \& Gurung, M. (1999). The ecology of fear: optimal foraging, game theory, and trophic interactions. Journal of mammalogy , 80 (2), 385-399.

Buck, J. C. (2019). Indirect effects explain the role of parasites in ecosystems. Trends in parasitology , 35 (10), 835-847.

Buck, J. C., \& Ripple, W. J. (2017). Infectious agents trigger trophic cascades. Trends in ecology \& evolution, 32(9), 681-694.

Burivalova, Z., Butler, R. A., \& Wilcove, D. S. (2018). Analyzing Google search data to debunk myths about the public's interest in conservation. Frontiers in Ecology and the Environment ,16 (9), 509-514. 
Butler, D. (2013). When Google got flu wrong: US outbreak foxes a leading web-based method for tracking seasonal flu. Nature ,494 (7436), 155-157.

Center for Disease Control. (2020). Health Equity Considerations and Racial and Ethnic Minority Groups. https://www.cdc.gov/coronavirus/2019-ncov/community/health-equity/race-ethnicity.html

Chen, K., Wang, M., Huang, C., Kinney, P. L., \& Anastas, P. T. (2020). Air pollution reduction and mortality benefit during the COVID-19 outbreak in China. The Lancet Planetary Health.

Choi, H., \& Varian, H. (2012). Predicting the present with Google Trends. Economic record, 88, 2-9.

Claudia, S., Stephan, G., Sarah, R. and Zheng, T. (2020). Google Searches Reveal Changing Consumer Food Sourcing in the COVID-19 Pandemic. Journal of Agriculture, Food Systems, and Community Development 9 .

Clinchy, M., Schulkin, J., Zanette, L. Y., Sheriff, M. J., McGowan, P. O., \& Boonstra, R. (2011). The neurological ecology of fear: insights neuroscientists and ecologists have to offer one another.Frontiers in behavioral neuroscience, 5,21 .

Clinchy, M., Sheriff, M. J., \& Zanette, L. Y. (2013). Predator-induced stress and the ecology of fear. Functional Ecology , 27 (1), 56-65.

Corlett, R. T., Primack, R. B., Devictor, V., Maas, B., Goswami, V. R., Bates, A. E., .. \& Cumming, G. S. (2020). Impacts of the coronavirus pandemic on biodiversity conservation. Biological Conservation, 246 , 108571.

Crawford, J., Butler-Henderson, K., Rudolph, J., \& Glowatz, M. (2020). COVID-19: 20 Countries' Higher Education Intra-Period Digital Pedagogy Responses. Journal of Applied Teaching and Learning (JALT) ,3 (1).

Curtis, V. A. (2014). Infection-avoidance behaviour in humans and other animals. Trends in Immunology, $35(10), 457-464$.

Dong, E., Du, H., \& Gardner, L. (2020). An interactive web-based dashboard to track COVID-19 in real time. The Lancet infectious diseases.

Frey, R., Hertwig, R., \& Rieskamp, J. (2014). Fear shapes information acquisition in decisions from experience. Cognition ,132 (1), 90-99.

Goel, S., Hofman, J. M., Lahaie, S., Pennock, D. M. and Watts, D. J. 2010. Predicting consumer behavior with Web search. - Proceedings of the National Academy of Sciences 107: 17486.

Gossling, S., Scott, D., \& Hall, C. M. (2020). Pandemics, tourism and global change: a rapid assessment of COVID-19. Journal of Sustainable Tourism, 1-20.

Haddaway, N. R., Wilcox, R. H., Heptonstall, R. E., Griffiths, H. M., Mortimer, R. J., Christmas, M., \& Dunn, A. M. (2012). Predatory functional response and prey choice identify predation differences between native/invasive and parasitised/unparasitised crayfish.PloS one, 7 (2), e32229.

Heerfordt, C., \& Heerfordt, I. M. (2020). Has there been an increased interest in smoking cessation during the first months of the COVID-19 pandemic? A Google Trends study. Public health, 183 , 6.

Hodges, C., Moore, S., Lockee, B., Trust, T., and Bond, A. (2020). The Difference Between Emergency Remote Teaching and Online Learning. Educause. March . Accessed 7/30/20.

Hooper, M. W., Napoles, A. M., \& Perez-Stable, E. J. (2020). COVID-19 and racial/ethnic disparities. Jama.

Hutchinson, J. M. C., and Gigerenzer G. (2005). Connecting behavioural biologists and psychologists: clarifying distinctions and suggestions for further work. Behav Processes 69:159-163 
Isaifan, R. J. (2020). The dramatic impact of Coronavirus outbreak on air quality: Has it saved as much as it has killed so far?. Global Journal of Environmental Science and Management, 6(3), 275-288.

Kandula, S., \& Shaman, J. (2019). Reappraising the utility of Google Flu Trends. PLoS Computational Biology , 15 (8), e1007258.

Kemp S (2005) Simple optimisation. Behav Processes 69:131-132.

Kristoufek, L. (2013). BitCoin meets Google Trends and Wikipedia: Quantifying the relationship between phenomena of the Internet era.Scientific reports , 3 (1), 1-7.

Lima, S. L., \& Dill, L. M. (1990). Behavioral decisions made under the risk of predation: a review and prospectus. Canadian journal of zoology , 68 (4), 619-640.

Lin, C. Y. (2020). Social reaction toward the 2019 novel coronavirus (COVID-19). Social Health and Behavior , 3 (1), 1.

Mann, M. E., Bradley, R. S., \& Hughes, M. K. (1999). Northern hemisphere temperatures during the past millennium: Inferences, uncertainties, and limitations. Geophysical research letters ,26 (6), 759-762.

Moore, A. J., Firn, J., \& Beckerman, A. (2017). Academic practice in ecology and evolution: Soliciting a new category of manuscript.Ecology and evolution, 7 (14), 5030.

Moore, J. L., Dickson-Deane, C. and Galyen, K. 2011. e-Learning, online learning, and distance learning environments: Are they the same? - The Internet and Higher Education 14: 129-135.

Nuti, S. V., Wayda, B., Ranasinghe, I., Wang, S., Dreyer, R. P., Chen, S. I., \& Murugiah, K. (2014). The use of google trends in health care research: a systematic review. PloS one , 9 (10), e109583.

Preis, T., Moat, H. S., \& Stanley, H. E. (2013). Quantifying trading behavior in financial markets using Google Trends. Scientific reports , 3, 1684.

Raifman, M. A., \& Raifman, J. R. (2020). Disparities in the population at risk of severe illness from covid-19 by race/ethnicity and income. American Journal of Preventive Medicine.

Rose, S. (2020). Medical student education in the time of COVID-19. Jama.

Rutz, C., Loretto, M. C., Bates, A. E., Davidson, S. C., Duarte, C. M., Jetz, W., .. \& Primack, R. B. (2020). COVID-19 lockdown allows researchers to quantify the effects of human activity on wildlife. Nature Ecology 83 Evolution, 1-4.

Wallace, R. M. 2003. Online Learning in Higher Education: a review of research on interactions among teachers and students. - Education, Communication \& Information 3: 241-280.

Weinstein, S. B., Buck, J. C., \& Young, H. S. (2018). A landscape of disgust. Science , 359 (6381), 1213-1214.

Winnie, J., Christianson, D., Creel, S., \& Maxwell, B. (2006). Elk decision-making rules are simplified in the presence of wolves.Behavioral Ecology and Sociobiology , 61 (2), 277.

Winter, A. Coronavirus pandemic has worsened racial disparities in education, lawmakers told. Ohio Capital Journal.

Vosen, S., \& Schmidt, T. (2011). Forecasting private consumption: survey-based indicators vs. Google trends. Journal of forecasting, 30 (6), 565-578.

Yancy, C. W. (2020). COVID-19 and African Americans. Jama.

Zambrano-Monserrate, M. A., Ruano, M. A., \& Sanchez-Alcalde, L. (2020). Indirect effects of COVID-19 on the environment. Science of the Total Environment, 138813. 
Zhang, W., Wang, Y., Yang, L., \& Wang, C. (2020). Suspending classes without stopping learning: China's education emergency management policy in the COVID-19 Outbreak.

Figure 1. The figure shows how the relative frequency of google searches on global topics related to money, death, and love changed over time. The panel on the left shows data from January 1 - June 30, 2019 (no COVID-19), while the panel on the right shows data from January 1 - June 30, 2020 (during the COVID-19 pandemic). Google Trends does not provide the total number of searchers for a term (Burivalova et al. 2018). They provide an adjusted proportion of searches. The thicker lines correspond to daily values, while the smaller line in the front corresponds to detrended weekly averages. In 2019, google searches on love were the most common followed by death and then by money. Users' interests remained stable through time except for a spike in searches on love around February 14, which corresponds to Saint Valentine's day. In 2020, the pattern is similar until mid March, with the exception of a spike in searches on topics related to death around January 26, which corresponds to increased interest in the death of basketball player Kobe Bryant who died in a helicopter accident. Gray bars represent the global number of confirmed COVID-19 cases (Dong et al. 2020). Note that as the number of COVID-19 cases increases, there is a shift in the relative interest in google searches. There is a small relative increase in searches related to money. Death becomes the top category, switching places with love. Data used in the figure is available at

https://github.com/maacevedo/covid19gtrends.

Figure 2. The figure shows how interest in online learning, measured as relative number google searches for "online learning" beginning January 2019 up to June 302020 in the USA, increased exponentially in parallel to the cumulative number of confirmed COVID-19 infections. Data used in the figure is available at

https://github.com/maacevedo/covid19gtrends.

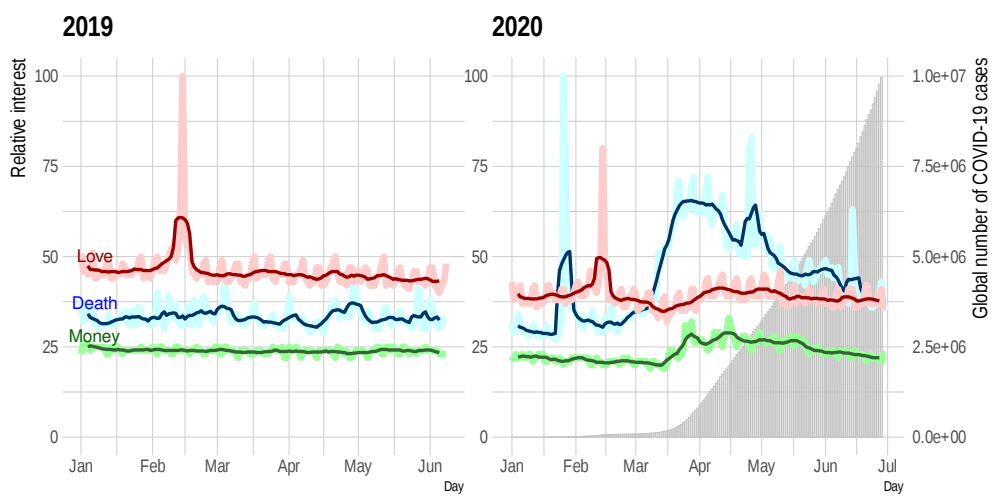




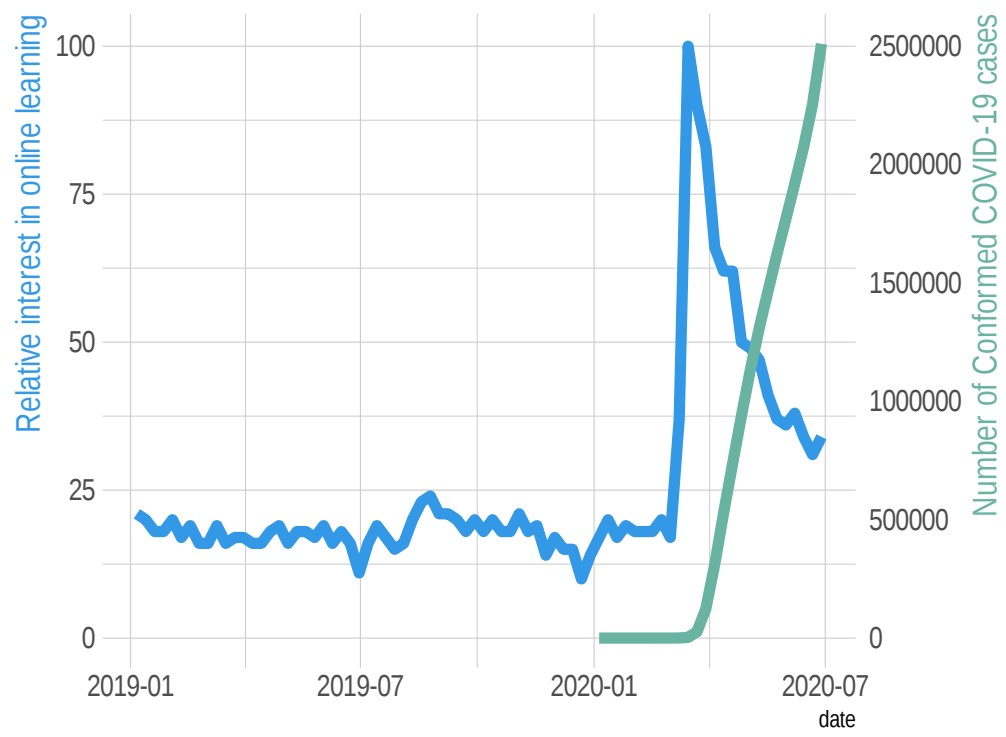

